\title{
Impact of early childhood malnutrition on the adult brain function: an ERP study
}

Roger, K. ${ }^{1}$, Vannasing, P. ${ }^{1}$, Tremblay, J. ${ }^{1}$, Bringas Vega, M. L. ${ }^{2}$, Bryce, C. P. ${ }^{3}$, Rabinowitz, A. G. ${ }^{4}$, Valdés-Sosa, P. A. ${ }^{2}$, Galler, J. R. ${ }^{5}$, \& Gallagher, A. ${ }^{1}$

${ }^{1}$ LION Lab, Sainte-Justine University Hospital Research Centre, University of Montreal, Montreal, QC, Canada

${ }^{2}$ The Clinical Hospital of Chengdu Brain Science Institute, MOE Key Lab for Neuroinformation, University of Electronic Science and Technology of China, Chengdu, China

${ }^{3}$ Barbados Nutrition Study, Bridgetown, Barbados

${ }^{4}$ Department of Neurology and Neurosurgery, McGill University, Montreal, QC, Canada

${ }^{5}$ Chester M. Pierce MD Division of Global Psychiatry, Massachusetts General Hospital, Boston, MA, United States

Corresponding author: Kassandra Roger (email: kassandra.roger@umontreal.ca)

\begin{abstract}
According to the World Health Organization, 45\% of deaths among children under 5 years of age are caused by childhood malnutrition, which affects 224 million children worldwide. The Barbados Nutrition Study (BNS) is a 50+year longitudinal study on a Barbadian cohort $(N=258)$ with histories of moderate to severe protein-energy malnutrition (PEM) in the first year of life and healthy controls. Interestingly, a recent BNS publication used quantitative electroencephalography (EEG) to show differences in brain function (lower alphal activity and higher theta, alpha2 and beta activity) in children who suffered from early PEM compared to healthy controls. However, the adult brain function following early childhood PEM has not been reported in this cohort. In the current study, EEG recordings were undertaken during a Go-No-Go task on a subsample of the BNS cohort $(n=55)$ at ages $45-51$ years. Evoked-related potentials (ERP) analyses show that, compared to the control group $(n=29)$, participants with histories of early PEM ( $n=24)$ presented with lower N2 amplitudes and a higher omission error rates, associated with conflict monitoring and attention deficits, respectively. These results may be linked to the attention and executive impairments that have been previously reported in this cohort.
\end{abstract}

\section{Keywords}

Early childhood malnutrition; Long-term outcomes; EEG; Go-No-Go; ERP; Inhibition; Attention 


\section{Introduction}

Two-hundred million children under five are affected by malnutrition worldwide, which makes this condition a critical global health concern (UNICEF, 2019). Protein energy malnutrition (PEM) is a specific type of malnutrition defined as an acute energy deficit due to deficiency of all macronutrients, and micronutrients in some cases (Atassi, 2019; Grover and Ee, 2009; Morley, 2018). Determining the effects of such an important health problem at a young age is therefore a priority.

Malnutrition has deleterious effects on cognitive abilities (Agarwal et al., 1992; Berkman et al., 2002; Galler et al., 1990; Kar et al., 2008; Mendez and Adair, 1999; Upadhyay et al., 1989). Malnutrition has also been associated with various effects on motor skills, behavior, social abilities, and mental health (Galler et al., 1983b; Hoorweg and Stanfield, 1976; Upadhyay et al., 1989). Some of these effects have been shown to persist into adolescence and adulthood (Galler et al., 2012a, 2012b; Waber et al., 2014b, 2014a; Walker et al., 2007).

Using electroencephalography (EEG), brain function alterations have also been associated with early childhood malnutrition. Nelson and colleagues (1959) reported a general slowing of the EEG's dominant rhythm in undernourished children from 4 to 44 months, as compared to a control group, which only partly normalized with adequate food intake, which was replicated in several other studies (Baraitser and Evans, 1969; Griesel et al., 1990; Robinson et al., 1995; Stoch et al., 1963), but only a few assessed the children at later timepoints in childhood. Bartel and colleagues (Bartel et al., 1979) studied malnourished children five to ten years after their hospitalization and confirmed that their rest EEG still had a significantly diminished alpha and increased theta and delta frequencies compared to a control group. In a recent study, brain function alterations in the resting state activity of previously malnourished 5-11 year old children of the BNS cohort were reported, namely an excess of theta, alpha 2 and beta frequencies and a decrease of alpha 1, which suggest a maturational lag in cortical development (Taboada-Crispi et al., 2018). It is clear from these behavioral and EEG findings that malnutrition at a young age has important acute deleterious effects on brain function, cognition and multiple other life fonctionning aspects. However, the effects of malnutrition on brain function in adulthood are still unknown.

The Barbados Nutrition Study (BNS) is a 50-year longitudinal study that has followed a Barbadian cohort hospitalized during the first year of life for a single episode of moderate to 
severe protein-energy malnutrition (PEM; Galler et al., 1987, 1983a) based on the Gomez classification (Gomez et al., 1955) as well as matched healthy controls who were former classmates of the PEM participants. The objectives of this study were to characterize the medical, neuropsychological, behavioral and brain effects of early PEM over the lifespan. The cohort comprises participants that were originally recruited between 1967 and 1972 when they were hospitalized as infants and subsequently enrolled in a government program that provided health and nutrition monitoring until the children reached 12 years of age (PEM group). The malnutrition episode was restricted to the first year of life. Control participants were classmates of the PEM children and were matched by age, sex, and handedness. All children in the PEM group achieved complete catch-up in physical growth by adolescence (Galler et al., 1987). Neuropsychological and psychiatric assessments revealed many cognitive, behavioral and mental health impairments associated with early childhood PEM including lower IQ, conduct problems and higher prevalence of affective and depressive symptoms as well as attention deficits (Galler et al., 1983a, 2010; Galler et al., 2012a). Additionally, most participants in the PEM group exhibit persistent attentional and executive problems during childhood, adolescence and adulthood compared to the control group (Galler et al., 1983a; Galler et al., 2012b; Galler and Ramsey, 1989). However, little is known about the brain function effects of early childhood malnutrition on this cohort.

The present study is an international Canada-United States-Cuba-Barbados collaboration. Our aim was to study the persistence of brain function alterations in adults who experienced moderate to severe PEM during the first year of life by comparing the brain activity in adults from the PEM and the control groups of the BNS cohort using evoked related potentials (ERPs). Considering the attention and executive impairments previously reported in the PEM group (Galler et al., 1983a; Galler et al., 2012b; Galler and Ramsey, 1989), we administered a Go-NoGo attention task during EEG recordings to specifically isolate those altered processes. In a GoNo-Go task, two ERPs components are typically studied, namely the N2 and P3 components. N2 is defined as the largest fronto-central negative polarity deflection between 200 and $450 \mathrm{~ms}$ and P3 is defined as the largest fronto-central positive polarity deflection between 350 and $600 \mathrm{~ms}$ (Grane et al., 2016; McLoughlin et al., 2010; Schmüser et al., 2016; Woltering et al., 2013). N2 and $\mathrm{P} 3$ are respectively associated with conflict monitoring (i.e. conflict between the prepotent response and required response) and inhibition response (i.e. cancellation of a planned or 
prepotent response) processes in an inhibition control task such as Go-No-Go, Stop signal, Stroop or Flanker task (Braver et al., 2001; Smith et al., 2008). Those components have been widely studied, notably in samples with ADHD (Grane et al., 2016; Johnstone et al., 2013; McLoughlin et al., 2010; Schmüser et al., 2016; Woltering et al., 2013) and are thought to be altered in individuals with attention and executive deficits. In the current study, we hypothesised that the PEM group will show smaller N2 and P3 component amplitudes compared to the healthy control group.

\section{Materials and Methods}

\section{Participants}

Fifty-five adults were recruited from the Barbados Nutrition Study (BNS) cohort, including 26 participants who experienced moderate to severe PEM during the first year of life (PEM group; male/female $=15 / 11$ ) and 29 healthy controls, former classmates of the PEM group, who no histories of malnutrition (Control group; male/female $=14 / 15$ ). The inclusion criteria for both groups were, as follows: (1) a normal birth weight $(>2500 \mathrm{~g}),(2)$ the absence of pre-or postnatal complications, (3) an Apgar score above or equal to 8, (4) no encephalopathic events during childhood and (5) no malnutrition or other serious childhood disease after the first year of life. Two participants of the PEM group had to be excluded, one due to heavy alcohol consumption the night before the testing and the other one did not complete the task. Groups did not differ in terms of age $(t=0.18, p=0.67)$ and gender (Male: $\chi^{2}=-0.58, p=0.57$; Female: $\chi^{2}=-$ $0.85, p=0.40)$. The sample's demographic characteristics are reported in Table 1. Table 2 shows no difference in the child demographic characteristics between our subsample and the rest of the BNS cohort. The subsample is therefore representative of the BNS population.

\section{Procedure}

EEG recordings took place at the Barbados Nutrition Study Clinic, Bridgetown, Barbados. The room was air conditioned and the temperature was maintained at $24^{\circ} \mathrm{C}$. Participants were seated in a comfortable chair and fitted with a 21-EEG $\mathrm{Ag} / \mathrm{AgCl}$ electrodes active cap, one vertical and one horizontal electro-oculogram (EOG), and one electrocardiogram (ECG). The EEG signal was recorded on the scalp using the actiCHamps amplifier and Brain Vision Recorder Software (version 1.20, Brain Products, GMbH, Gilching, Germany). EEG channels were positioned according to the 10-20 system (Fz, Cz, Pz, Oz, Fp1/2, F3/4, C3/4, P3/4, O1/2, F7/8, $\mathrm{T} 3 / 4, \mathrm{~T} 5 / 6$, plus ground and reference). The impedance was kept under $10 \mathrm{k} \Omega$. A near-infrared 
spectroscopy (NIRS) recording was performed simultaneously with the EEG. However, the NIRS data are not included in the current article. A Go-No-Go task was performed during the EEGNIRS recording.

\section{Go-No-Go task}

The Go-No-Go task was presented using Presentation (version 20.2, Neurobehavioral Systems; see figure 1). Participants were instructed to click a mouse with their dominant hand's index finger as fast as possible whenever a letter (Go trial) appeared on the screen, but to withhold from responding if the letter was an X (No-Go trial). Each letter was presented pseudorandomly for $500 \mathrm{~ms}$ and disappeared as soon as a motor response was made. The interstimulus interval varied randomly between 700 and 1000 ms. The task was built in a block design in which each block of 20 stimuli was delimited by a resting period that varied randomly between 15 and $21 \mathrm{sec}$. A block design was used rather than a single trial paradigm to accommodate both the EEG and NIRS signals. The task consisted of 14 No-Go blocks, and 14 Go blocks. The NoGo blocks included $30 \%$ of No-Go trials (6 X) and $70 \%$ of Go trials (14 letters) presented pseudorandomly. The Go blocks included Go trials only. Each participant went through a practice trial of one No-Go block that included feedback before the actual task. Overall, 28 blocks were presented to each participant, for a total of 476 Go and 84 No-Go trials (total of 560 letters). Additional blocks were presented so that at least 70 No-Go trials were correctly inhibited to ensure a good signal to noise ratio. Three behavioral variables were computed based on the 28 blocks of the task (without additional blocks): reaction time (RT), No-Go accuracy and Go accuracy.

\section{EEG recording and data processing}

The EEG signal was recorded from the scalp using at $500 \mathrm{~Hz}$ sampling rate and referenced to electrode FCz. The data pre-processing was done using Brain Vision Analyzer (Brain Products, Munich, Germany). Data was first filtered offline between 0.5 and $35 \mathrm{~Hz}$ using a Butterworth filter with a notch filter at $50 \mathrm{~Hz}$ to remove any electrical interference. Ocular artefacts were then removed by subtracting the corresponding components using Independent Component Analysis (ICA). The data was then re-sampled at $512 \mathrm{~Hz}$ and re-referenced to the average reference. Each trial was segmented from -500 to $1000 \mathrm{~ms}$ after stimulus onset. DC detrend was applied to the data to remove the signal drift. 
An artifact correction was then performed to reject any segment with artifacts for each channel individually. Any segment with a voltage step $>50 \mu \mathrm{v} / \mathrm{ms}$ was removed. The maximum amplitude allowed was $100 \mu \mathrm{v}$ and the minimum amplitude allowed was $-100 \mu \mathrm{v}$. A trained Ph.D. candidate (K.R.) then performed a visual inspection of the signal to detect any remaining artifacts and validate the artifact correction. Every incorrect trial, namely every No-Go followed by a motor response or Go without a motor response, was also rejected. A baseline correction was further applied using $200 \mathrm{~ms}$ before stimulus onset. Trials were then averaged in Correct NoGo $(M=69.6$ trials, $S D=10.5)$ and Correct Go trials $(M=471.3, S D=67.3)$.

ERP analysis. For each participant, a semi-automatic peak detection for the N2 and P3 ERP components was first performed on Correct No-Go and Correct Go trials individually on Fz, $\mathrm{Cz}$ and $\mathrm{FCz}$ electrodes, where the components have previously been reported (Donkers and van Boxtel, 2004; Falkenstein et al., 1999). N2 was defined as the largest fronto-central negative polarity deflection between 200 and $450 \mathrm{~ms}$ and P3 was defined as the largest fronto-central positive polarity deflection between 350 and 600ms (Grane et al., 2016; McLoughlin et al., 2010; Schmüser et al., 2016; Woltering et al., 2013). The peaks were reviewed by a trained Ph.D. candidate (K.R.) and an expert in EEG processing (P.V.). The mean amplitude $\pm 10 \mathrm{~ms}$ around the peak and the latency of each peak was extracted and used for statistical analyses. A topographic T-test (without correction for multiple comparisons) was performed to compare amplitude topographies between groups (PEM vs Control). BrainVision assisted t-tests were computed on amplitude topographies during N2 and P3 components for No-Go and Go conditions individually when the differences between groups were maximal (see figures 2 and 3).

\section{Statistical analyses}

For the behavioral measures (performance at the Go-No-Go task), three separate independent sample t-tests with group as the between-subjects factor were conducted for the reaction time, Go accuracy and No-Go accuracy. For the ERP components, four mixed ANOVA [3 (Electrode: Fz, Cz, FCz) x 2 (Condition: No-Go, Go) x 2 (Group: Controls, PEM)] were conducted separately for N2 and P3 and for their amplitude and latency. The significant p-value was set to $p \leq 0.05$. The extreme outliers, defined as a value that is over 3 times the interquartile range, were winsorized as suggested by Wilcox and colleagues (2012). Greenhouse-Geisser adjustment was applied if the assumption of sphericity was violated (Mauchley's test statistic significant at $p<0.05)$ and the Bonferroni correction was applied for multiple comparisons. Mann- 
Withney U nonparametric test was used if the Shapiro-Wilk normality test was violated. If nonparametric and parametric tests provided similar results, parametric tests were reported. Statistical analyses were performed using SPSS (version 25).

\section{Results}

\section{Behavioral results}

Statistical analyses revealed a significant difference between groups on Go accuracy ( $U=462, p=0,041$ ), with greater Go accuracy for the control group compared to the PEM group. Table 3 shows the means and standard deviations of the behavioral measures.

\section{N2}

Figure 4 and 5 show the waveform of the N2 and P3 components for each group during the NoGo and Go conditions, respectively.

Amplitude. A three-way ANOVA revealed a main effect of Electrodes $\left(F(2,102)=7.745, p=0.004, \eta_{\mathrm{p}}^{2}=0.132\right)$ with pairwise comparisons indicating a smaller amplitude for Fz compared to FCz $(p<0.001)$ and compared to $\mathrm{Cz}$ ( $p=0.060$, statistical tendency). There was also a main effect of Condition $\left(F(1,51)=30.219, p<0.001, \eta_{\mathrm{p}}{ }^{2}=0.372\right)$ with the NoGo condition generating a larger N2 amplitude than the Go condition, according to pairwise comparisons. Significant interactions between Condition and Group $(F(1,51)=5.404, p=0.024$, $\left.\eta_{\mathrm{p}}{ }^{2}=0.096\right)$ and between Electrode and Condition $\left(F(2,102)=5.061, p=0.020, \eta_{\mathrm{p}}{ }^{2}=0.090\right)$ were found. Appropriate t-tests and repeated measures ANOVA were conducted to further explore these interactions.

For the Condition x Group interaction, independent t-tests revealed a significant difference of the N2 amplitude between the two groups but only in the No-Go condition [No-Go: $t(51)=1.959, p=0.056$; Go: $(t(51)=0.147, p=0.883]$. During the No-Go condition, the amplitude of N2 was significantly larger for the control group compared to the PEM group. 
For the Electrode $\mathrm{x}$ Condition interaction, the repeated measure ANOVA revealed a smaller amplitude for $\mathrm{Fz}$ compared to $\mathrm{FCz}(p<0,001)$ and $\mathrm{Cz}(p=0,035)$ during the No-Go condition $(F(2,104)=9,103, p=0,002)$, but only a smaller amplitude for Fz compared to $\mathrm{FCz}$ $(p=0,027)$ during the Go condition $(F(2,104)=3,479, p=0,058)$.

Latency. The three-way ANOVA showed a main effect of Electrodes

$\left(F(2,102)=13.943, p<0.001, \eta_{\mathrm{p}}{ }^{2}=0.215\right)$ with pairwise comparisons indicating a shorter latency for $\mathrm{Cz}$ compared to $\mathrm{FCz}(p=0.001)$ and compared to $\mathrm{Fz}(p<0.001)$. There was also a main effect of Condition $\left(F(1,51)=22.524, p<0.001, \eta_{\mathrm{p}}^{2}=0.306\right)$ with the No-Go condition generating a longer N2 latency than the Go condition. No interaction was significant, and there was no significant nutrition group effect.

\section{P3}

Amplitude. The three-way ANOVA revealed a main effect of Electrodes $\left(F(2,102)=25.811, p<0.001, \eta_{\mathrm{p}}{ }^{2}=0.336\right)$ with pairwise comparisons indicating a smaller amplitude for $\mathrm{Fz}$ compared to $\mathrm{FCz}(p<0.001)$ and compared to $\mathrm{Cz}(p=0.001)$. There was also a main effect of Condition $\left(F(1,51)=195.127, p<0.001, \eta_{\mathrm{p}}{ }^{2}=0.793\right)$ with the No-Go condition generating a larger P3 amplitude than the Go condition, according to pairwise comparisons. There was also a significant interaction between Electrode and Condition $\left(F(2,102)=7.667, p=0.004, \eta_{\mathrm{p}}{ }^{2}=0.131\right)$. A repeated measures ANOVA was conducted as posthoc analysis to further explore this interaction. For the No-Go condition $\left(F(2,104)=18.912, p<0.001, \eta_{\mathrm{p}}^{2}=0.267\right)$, it showed that $\mathrm{P} 3$ amplitude was larger at $\mathrm{FCz}$ compared to $\mathrm{Fz}(p<0.001)$ and $\mathrm{Cz}(p=0.014)$, and that it was larger at $\mathrm{Cz}$ compared to $\mathrm{Fz}(p=0.027)$. For the Go condition $\left(F(2,104)=26.076, p<0.001, \eta_{\mathrm{p}}{ }^{2}=0.334\right)$, it showed that $\mathrm{P} 3$ amplitude was smaller at Fz compared to $\mathrm{FCz}(p<0.001)$ and $\mathrm{Cz}(p<0.001)$.

Latency. No significant main effects or interactions were obtained for the P3 latency three-way ANOVA. Table 4, 5 and 6 show the means and standard deviations of the ERP measures for each condition for $\mathrm{Fz}, \mathrm{Cz}$ and $\mathrm{FCz}$, respectively.

\section{Discussion}

The main objective of this study was to compare the brain activity of adults who experienced moderate to severe PEM during the first year of life and healthy controls with no histories of malnutrition using a Go-No-Go inhibition task. We hypothesized that the PEM group 
would show altered neural response associated with attention and inhibition (N2 and P3 components) during the task. The hypothesis was partially confirmed, since we observed a reduction of $\mathrm{N} 2$ amplitude during the No-Go condition in the PEM group compared to the control group, but no difference in P3. Overall, results of the Go-No-Go task revealed a main effect of Condition for both components (N2 and P3) in both groups (PEM and Control). This is typical result for a Go-No-Go task, indicating that the No-Go condition induces a genuine inhibition response process which is delaying the onset and amplifying the N2 and P3 components (Bokura et al., 2001; Eimer, 1993; Schmüser et al., 2016).

The N2 amplitude was smaller in the PEM group compared to the control group during the No-Go condition. This result has also been found in adults and children with ADHD (Brandeis et al., 2002; Fallgatter et al., 2004; Gow et al., 2012; Woltering et al., 2013). There is debate amongst the scientific community on the cognitive process underlying the N2 component. Although some authors argue that $\mathrm{N} 2$ is related to the inhibition process (i.e. cancellation of a planned or prepotent response; Eimer, 1993; Falkenstein et al., 1999), more recent studies point to an association between $\mathrm{N} 2$ and conflict monitoring (i.e. conflict between the prepotent response and required response; Donkers and van Boxtel, 2004; Enriquez-Geppert et al., 2010; Groom and Cragg, 2015; Huster et al., 2013; Woltering et al., 2013). According to the conflict monitoring hypothesis, an inhibition task such as Go-No-Go should evoke a N2 component because of the unbalanced ratio between Go and No-Go trials, which would lead to the creation of a prepotent response (Go) that conflicts with the infrequent inhibition of this response (No-Go) and not because of the inhibition process per se (Braver et al., 2001). Conflict monitoring is however closely related to attention since it is responsible for triggering cognitive control changes by adjusting attention levels to optimize performance and prevent subsequent conflict (Botvinick et al., 2001). According to these models, our results can be interpreted as an impairment in conflict monitoring and/or attention following early childhood malnutrition.

Surprisingly, the ERP results showed no difference between the two nutrition groups in P3 amplitude or latency. P3 component is usually considered to be a marker of response inhibition processing and evaluation (Groom and Cragg, 2015; Huster et al., 2013). In studies of ADHD using a Go-no-Go task, both components, N2 and P3, are typically altered (Johnstone et al., 2013; Woltering et al., 2013). However, the reduced N2 amplitude in the PEM group and similar P3 amplitude between groups is in line with the behavioral results. Indeed, in the current study, Go 
accuracy was significantly lower in the PEM group compared to the control group, revealing that adults who suffered from early childhood malnutrition committed more omission errors than controls. No difference in commission error rate was found. Omission errors are usually attributed to impairments in attention and vigilance whereas commission errors are associated with inhibition deficits. Therefore, early childhood malnutrition may be associated with diminished attention and vigilance rather than altered inhibition skills (Doehnert et al., 2013; Grane et al., 2016; McLoughlin et al., 2010; Valko et al., 2009). Furthermore, no differences in reaction times were found between our groups. Slower reaction times have been consistently reported in populations with attentional and inhibition difficulties and are associated with hyperactivity and impulsivity (Barkley et al., 2008; McLoughlin et al., 2010; Rubia et al., 2007; Schmüser et al., 2016; Tamm et al., 2012; Wiersema et al., 2006). Overall, the behavioral results suggest attention deficits with normal inhibition skills in adults who experienced early childhood malnutrition. Nevertheless, we cannot rule out that the PEM group developed compensatory mechanisms to overcome inhibition difficulties.

The ERP and behavioral results are in line with the persistent attention deficits previously reported in our cohort during childhood, adolescence and adulthood (Galler et al., 2012b, 1990, 1983a; Galler and Ramsey, 1989; Peter et al., 2016). Attention deficits have also been reported in other studies assessing the neurocognitive profile of malnourished population (Kar et al., 2008; Kesari et al., 2010; Richardson et al., 1972; Wang et al., 2016). Although the PEM group had persistent attention deficits in the prior BNS publications (e.g. 69\% had at least one score falling within the clinical range for attention disorder at the Continuous Performance Test or CPT), only $8 \%$ achieved a clinical diagnosis of ADHD (Galler et al., 2012b). Attention deficits seem highly more prevalent in our cohort than hyperactive/impulsive ADHD symptoms. Interestingly, a recent study assessing neuropsychological functions in the BNS cohort showed that cognitive flexibility was more altered than inhibition (Waber et al., 2014a). This neuropsychological profile could explain why we did not find any electrophysiological marker of inhibition deficits (P3 or commission errors).

The altered electrophysiological marker found in this study is also coherent with literature on brain function effects following childhood malnutrition. Indeed, several studies show that childhood malnutrition is associated with slowing of the EEG's dominant rhythm in infancy (Baraitser and Evans, 1969; Griesel et al., 1990; Nelson, 1959; Robinson et al., 1995; Stoch et al., 
1963) and electrophysiological alterations that persist in childhood even with food rehabilitation (Bartel et al., 1979; Taboada-Crispi et al., 2018). ERP anormalities were also found following childhood malnutrition with a higher relative abnormality of their auditory evoked potentials compared to controls (Barnet et al., 1978; McDonald, Joffe, Barnet and Flinn, 2007). We expand knowledge in this field by showing brain function deficits still perceptible in adulthood.

This study has several limitations. First, the small sample size does not allow us to conclude with certainty that the results were not due to lack of statistical power. Nevertheless, the effect size is moderate for the N2 amplitude difference between the groups $(d=0.55)$. Also, due to the small sample size, we could not adjust our statistical analyses for age, gender and handedness. Though we found no differences between the two groups on those variables, we cannot exclude that these variables might have had an effect on our results. The results reported here are specific to the N2 and P3 electrophysiological markers. Potential other electrophysiological differences between our groups might exist and would allow us to identify additional brain markers of early childhood malnutrition (e.g. time frequency, source level, connectivity). Indeed, using source localization analysis on our data would allow to explore more precisely at the source level the brain function temporal dynamics of the executive function. However, at least 64 electrodes would be needed to apply source analysis. Further analyses will be performed to better characterize and compare brain function in both groups.

\section{Conclusion}

In sum, this study shows that adults who experienced early childhood malnutrition in the first year of life demonstrate different brain response patterns during a response inhibition task compared to healthy controls. This adds to the existent literature on cognitive and neural outcomes following early childhood malnutrition, suggesting that attention and conflict monitoring, two cognitive control processes, are still altered in adulthood. Malnutrition can have deleterious effects on cognition, physical and mental health, behavior and brain function even if restricted to the first year of life. Considering the impact of persisting cognitive alterations on the quality of life, more research is needed to better characterize the brain markers and clinical

profile associated with early childhood malnutrition in order to develop a disease progression model applicable to various vulnerable populations. 


\section{Statement of Ethical Standards}

This study has been performed in accordance with the ethical standards laid down in the 1964

Declaration of Helsinki and its later amendments. All study participants provided written informed consent and were compensated for their time and travel expenses. This study was approved by the Massachusetts General Hospital IRB (IRB Protocol 2015P000329/MGH), Hôpital Sainte-Justine and Centro de Neurosciencias de Cuba' (CNEURO) Ethics' committees. 


\section{References}

Agarwal, D.K., Awasthy, A., Upadhyay, S.K., Singh, P., Kumar, J., Agarwal, K.N., 1992.

Growth, behavior, development and intelligence in rural children between 1-3 years of life. Indian Pediatr. 29, 467-80.

Atassi, H., 2019. Protein-Energy Malnutrition: Background, Pathophysiology, Etiology [WWW Document]. Medscape. URL https://emedicine.medscape.com/article/1104623-overview (accessed 8.18.19).

Baraitser, M., Evans, D.E., 1969. The effect of undernutrition on brain-rhythm development. South African Med. J. 43, 56-58.

Barkley, R.A., Murphy, K.R., Fischer, M., 2008. ADHD in adults : what the science says. Guilford Press.

Barnet, A.B., Weiss, I.P., Sotillo, M. V., Ohlrich, E.S., Shkurovich, Z.M., Cravioto, J., 1978. Abnormal auditory evoked potentials in early infancy malnutrition. Science (80-. ). 201, 450-452. https://doi.org/10.1126/science.96529

Bartel, P.R., Griesel, R.D., Freiman, I., Rosen, E.U., Geefhuysen, J., 1979. Long-term effects of kwashiorkor on the electroencephalogram. Am. J. Clin. Nutr. 32, 753-757. https://doi.org/10.1093/ajcn/32.4.753

Berkman, D.S., Lescano, A.G., Gilman, R.H., Lopez, S.L., Black, M.M., 2002. Effects of stunting, diarrhoeal disease, and parasitic infection during infancy on cognition in late childhood: a follow-up study. Lancet 359, 564-571. https://doi.org/10.1016/S01406736(02)07744-9

Bokura, H., Yamaguchi, S., Kobayashi, S., 2001. Electrophysiological correlates for response inhibition in a Go/NoGo task. Clin. Neurophysiol. 112, 2224-2232. https://doi.org/10.1016/S1388-2457(01)00691-5

Botvinick, M.M., Carter, C.S., Braver, T.S., Barch, D.M., Cohen, J.D., 2001. Conflict monitoring and cognitive control. Psychol. Rev. 108, 624-652. https://doi.org/10.1037/0033295X.108.3.624

Brandeis, D., van Leeuwen, T.H., Steger, J., Imhof, K., Steinhausen, H.C., 2002. Mapping brain functions of ADHD children. Int. Congr. Ser. 1232, 649-654. https://doi.org/10.1016/S0531-5131(01)00673-2 
Braver, T.S., Barch, D.M., Gray, J.R., Molfese, D.L., Snyder, A., 2001. Anterior Cingulate Cortex and Response Conflict: Effects of Frequency, Inhibition and Errors. Cereb. Cortex 11, 825-836. https://doi.org/10.1093/cercor/11.9.825

Doehnert, M., Brandeis, D., Schneider, G., Drechsler, R., Steinhausen, H.C., 2013. A neurophysiological marker of impaired preparation in an 11-year follow-up study of attention-deficit/hyperactivity disorder (ADHD). J. Child Psychol. Psychiatry Allied Discip. 54, 260-270. https://doi.org/10.1111/j.1469-7610.2012.02572.x

Donkers, F.C.L., van Boxtel, G.J.M., 2004. The N2 in go/no-go tasks reflects conflict monitoring not response inhibition. Brain Cogn. 56, 165-176.

https://doi.org/10.1016/J.BANDC.2004.04.005

Eimer, M., 1993. Effects of attention and stimulus probability on ERPs in a Go/Nogo task. Biol. Psychol. 35, 123-138. https://doi.org/10.1016/0301-0511(93)90009-W

Enriquez-Geppert, S., Konrad, C., Pantev, C., Huster, R.J., 2010. Conflict and inhibition differentially affect the N200/P300 complex in a combined go/nogo and stop-signal task. Neuroimage 51, 877-887. https://doi.org/10.1016/J.NEUROIMAGE.2010.02.043

Falkenstein, M., Hoormann, J., Hohnsbein, J., 1999. ERP components in Go/Nogo tasks and their relation to inhibition. Acta Psychol. (Amst). 101, 267-291. https://doi.org/10.1016/S00016918(99)00008-6

Fallgatter, A.J., Ehlis, A.C., Seifert, J., Strik, W.K., Scheuerpflug, P., Zillessen, K.E., Herrmann, M.J., Warnke, A., 2004. Altered response control and anterior cingulate function in attention-deficit/hyperactivity disorder boys. Clin. Neurophysiol. 115, 973-981. https://doi.org/10.1016/j.clinph.2003.11.036

Galler, J.R., Bryce, C.P., Waber, D., Hock, R.S., Exner, N., Eaglesfield, D., Fitzmaurice, G., Harrison, R., 2010. Early childhood malnutrition predicts depressive symptoms at ages 1117. J. Child Psychol. Psychiatry 51, 789-798. https://doi.org/10.1111/j.14697610.2010.02208.x

Galler, J.R., Bryce, C.P., Waber, D.P., Hock, R.S., Harrison, R., Eaglesfield, G.D., Fitzmaurice, G., 2012a. Infant malnutrition predicts conduct problems in adolescents. Nutr. Neurosci. 15, 186-192. https://doi.org/10.1179/1476830512Y.0000000012 
Galler, J.R., Bryce, C.P., Zichlin, M.L., Fitzmaurice, G., Eaglesfield, G.D., Waber, D.P., 2012 b. Infant Malnutrition Is Associated with Persisting Attention Deficits in Middle Adulthood. J. Nutr. 142, 788-794. https://doi.org/10.3945/jn.111.145441

Galler, J.R., Ramsey, F., 1989. A follow-up study of the influence of early malnutrition on development: behavior at home and at school. J. Am. Acad. Child Adolesc. Psychiatry 28, 254-261. https://doi.org/10.1097/00004583-198903000-00018

Galler, J.R., Ramsey, F., Solimano, G., Lowell, W.E., 1983a. The Influence of Early Malnutrition on Subsequent Behavioral Development: II. Classroom Behavior. J. Am. Acad. Child Psychiatry 22, 16-22. https://doi.org/10.1097/00004583-198301000-00003

Galler, J.R., Ramsey, F., Solimano, G., Lowell, W.E., Mason, E., 1983b. The Influence of Early Malnutrition on Subsequent Behavioral Development: I. Degree of Impairment in Intellectual Performance. J. Am. Acad. Child Psychiatry 22, 8-15. https://doi.org/10.1097/00004583-198301000-00002

Galler, J.R., Ramsey, F.C., Forde, V., Salt, P., Archer, E., 1987. Long-term effects of early kwashiorkor compared with marasmus. II. Intellectual performance. J. Pediatr. Gastroenterol. Nutr. 6, 847-854. https://doi.org/10.1097/00005176-198711000-00005

Galler, J.R., Ramsey, F.C., Morley, D.S., Archer, E., Salt, P., 1990. The long-term effects of early kwashiorkor compared with marasmus. IV. performance on the national high school entrance examination. Pediatr. Res. 28, 235-239. https://doi.org/10.1203/00006450199009000-00018

Gomez, F., Galvan, R.R., Cravioto, J., Frenk, S., 1955. Malnutrition in infancy and childhood, with special reference to kwashiorkor. Adv. Pediatr. 7, 131-69.

Gow, R. V., Rubia, K., Taylor, E., Vallée-Tourangeau, F., Matsudaira, T., Ibrahimovic, A., Sumich, A., 2012. Abnormal Centroparietal ERP Response in Predominantly MedicationNaive Adolescent Boys With ADHD During Both Response Inhibition and Execution. J. Clin. Neurophysiol. 29, 181-189. https://doi.org/10.1097/WNP.0b013e31824e1025

Grane, V.A., Brunner, J.F., Endestad, T., Aasen, I.E.S., Kropotov, J., Knight, R.T., Solbakk, A.K., 2016. ERP Correlates of Proactive and Reactive Cognitive Control in Treatment-Naïve Adult ADHD. PLoS One 11, e0159833. https://doi.org/10.1371/journal.pone.0159833 
Griesel, R.D., Richter, L.M., Belciug, M., 1990. Electro-encephalography and performance in a poorly nourished South African population. S. Afr. Med. J. 78, 539-543.

Groom, M.J., Cragg, L., 2015. Differential modulation of the N2 and P3 event-related potentials by response conflict and inhibition. Brain Cogn. 97, 1-9.

https://doi.org/10.1016/J.BANDC.2015.04.004

Grover, Z., Ee, L.C., 2009. Protein Energy Malnutrition. Pediatr. Clin. North Am. https://doi.org/10.1016/j.pcl.2009.07.001

Hoorweg, J., Stanfield, J.P., 1976. The Effects of Protein Energy Malnutrition in Early Childhood on Intellectual and Motor Abilities in Later Childhood and Adolescence. Dev. Med. Child Neurol. 18, 330-350. https://doi.org/10.1111/j.1469-8749.1976.tb03656.x

Huster, R.J., Enriquez-Geppert, S., Lavallee, C.F., Falkenstein, M., Herrmann, C.S., 2013. Electroencephalography of response inhibition tasks: Functional networks and cognitive contributions. Int. J. Psychophysiol. https://doi.org/10.1016/j.ijpsycho.2012.08.001

Johnstone, S.J., Barry, R.J., Clarke, A.R., 2013. Ten years on: A follow-up review of ERP research in attention-deficit/hyperactivity disorder. Clin. Neurophysiol. 124, 644-657. https://doi.org/10.1016/J.CLINPH.2012.09.006

Kar, B.R., Rao, S.L., Chandramouli, B.A., 2008. Cognitive development in children with chronic protein energy malnutrition. Behav. Brain Funct. 4, 31. https://doi.org/10.1186/1744-90814-31

Kesari, K., Handa, R., Prasad, R., 2010. Effect of undernutrition on cognitive development of children., International Journal of Food, Nutrition and Public Health.

McDonald, C.G., Joffe, C.L., Barnet, A.B., Flinn, J.M., 2007. Abnormal flash visual evoked potentials in malnourished infants: An evaluation using principal component analysis. Clin. Neurophysiol. 118, 896-900. https://doi.org/10.1016/j.clinph.2007.01.006

McLoughlin, G., Albrecht, B., Banaschewski, T., Rothenberger, A., Brandeis, D., Asherson, P., Kuntsi, J., 2010. Electrophysiological evidence for abnormal preparatory states and inhibitory processing in adult ADHD. Behav. Brain Funct. 6, 66. https://doi.org/10.1186/1744-9081-6-66 
Mendez, M.A., Adair, L.S., 1999. Severity and Timing of Stunting in the First Two Years of Life Affect Performance on Cognitive Tests in Late Childhood. J. Nutr. 129, 1555-1562. https://doi.org/10.1093/jn/129.8.1555

Morley, J.E., 2018. Protein-Energy Undernutrition (PEU) - Nutritional Disorders - MSD Manual Professional Edition [WWW Document]. MSD Manuals. URL https://www.msdmanuals.com/professional/nutritional-disorders/undernutrition/proteinenergy-undernutrition-peu (accessed 8.18.19).

Nelson, G.K., 1959. The electroencephalogram in kwashiorkor. Electroencephalogr. Clin. Neurophysiol. 11, 73-84. https://doi.org/10.1016/0013-4694(59)90009-4

Richardson, S.A., Birch, H.G., Grabie, E., Yoder, K., 1972. The Behavior of Children in School Who Were Severely Malnourished in the First Two Years of Life, Source: Journal of Health and Social Behavior.

Robinson, S., Young, R., Golden, M., 1995. Electrophysiological assessment of brain function in severe malnutrition. Acta Pædiatrica 84, 1245-1251. https://doi.org/10.1111/j.16512227.1995.tb13542.x

Rubia, K., Smith, A., Taylor, E., 2007. Performance of Children with Attention Deficit Hyperactivity Disorder (ADHD) on a Test Battery of Impulsiveness. Child Neuropsychol. 13, 276-304. https://doi.org/10.1080/09297040600770761

Schmüser, L., Sebastian, A., Mobascher, A., Lieb, K., Feige, B., Tüscher, O., 2016. Data-driven analysis of simultaneous EEG/fMRI reveals neurophysiological phenotypes of impulse control. Hum. Brain Mapp. 37, 3114-3136. https://doi.org/10.1002/hbm.23230

Smith, J.L., Johnstone, S.J., Barry, R.J., 2008. Movement-related potentials in the Go/NoGo task: The P3 reflects both cognitive and motor inhibition. Clin. Neurophysiol. 119, 704-714. https://doi.org/10.1016/J.CLINPH.2007.11.042

Stoch, M.B., Smythe, P.M., Ivanovic, D.M., 1963. Does undernutrition during infancy inhibit brain growth and subsequent intellectual development? Nutrition 12, 568-571. https://doi.org/10.1016/S0899-9007(96)00123-2 
Taboada-Crispi, A., Bringas-Vega, M.L., Bosch-Bayard, J., Galán-García, L., Bryce, C., Rabinowitz, A.G., Prichep, L.S., Isenhart, R., Calzada-Reyes, A., VIrues-Alba, T., Guo, Y., Galler, J.R., Valdés-Sosa, P.A., 2018. Quantitative EEG tomography of early childhood malnutrition. Front. Neurosci. 12. https://doi.org/10.3389/fnins.2018.00595

Tamm, L., Narad, M.E., Antonini, T.N., O’Brien, K.M., Hawk, L.W., Epstein, J.N., 2012. Reaction Time Variability in ADHD: A Review. Neurotherapeutics 9, 500-508. https://doi.org/10.1007/s13311-012-0138-5

UNICEF, 2019. Malnutrition [WWW Document]. April. URL https://data.unicef.org/topic/nutrition/malnutrition/ (accessed 7.26.19).

Upadhyay, S.K., Agarwal, K.N., Agarwal, D.K., 1989. Influence of malnutrition on social maturity, visual motor coordination \&amp; memory in rural school children. Indian J. Med. Res. 90, 320-7.

Valko, L., Doehnert, M., Müller, U.C., Schneider, G., Albrecht, B., Drechsler, R., Maechler, M., Steinhausen, H.C., Brandeis, D., 2009. Differences in neurophysiological markers of inhibitory and temporal processing deficits in children and adults with ADHD. J. Psychophysiol. 23, 235-246. https://doi.org/10.1027/0269-8803.23.4.235

Waber, D.P., Bryce, C.P., Fitzmaurice, G.M., Zichlin, M.L., McGaughy, J., Girard, J.M., Galler, J.R., 2014a. Neuropsychological outcomes at midlife following moderate to severe malnutrition in infancy. Neuropsychology 28, 530-540. https://doi.org/10.1037/neu0000058

Waber, D.P., Bryce, C.P., Girard, J.M., Zichlin, M., Fitzmaurice, G.M., Galler, J.R., $2014 b$. Impaired IQ and Academic Skills in Adults Who Experienced Moderate to Severe Infantile Malnutrition: A Forty-Year Study. Nutr. Neurosci. 17, 58-64. https://doi.org/10.1179/1476830513Y.0000000061

Walker, S.P., Chang, S.M., Powell, C.A., Simonoff, E., Grantham-McGregor, S.M., 2007. Early childhood stunting is associated with poor psychological functioning in late adolescence and effects are reduced by psychosocial stimulation. J. Nutr. 137, 2464-9. https://doi.org/137/11/2464 [pii] 
Wang, C., An, Y., Yu, H., Feng, L., Liu, Q., Lu, Y., Wang, H., Xiao, R., 2016. Association between Exposure to the Chinese Famine in Different Stages of Early Life and Decline in Cognitive Functioning in Adulthood. Front. Behav. Neurosci. 10, 146. https://doi.org/10.3389/fnbeh.2016.00146

Wiersema, R., van der Meere, J., Antrop, I., Roeyers, H., 2006. State Regulation in Adult ADHD: An Event-related Potential Study. J. Clin. Exp. Neuropsychol. 28, 1113-1126. https://doi.org/10.1080/13803390500212896

Wilcox, R.R., 2012. Introduction to robust estimation and hypothesis testing. Academic Press.

Woltering, S., Liu, Z., Rokeach, A., Tannock, R., 2013. Neurophysiological differences in inhibitory control between adults with ADHD and their peers. Neuropsychologia 51, 18881895. https://doi.org/10.1016/J.NEUROPSYCHOLOGIA.2013.06.023 
Table 1

Demographic Characteristics of NIRS Participants - BNS Summer Study 2018

\begin{tabular}{lcccc}
\hline Characteristic & PEM & Control & t-test $/ \chi^{2}$ & $p$ \\
\hline$N$ & 24 & 29 & & \\
Males [N (\%)] & $13(54.17)$ & $14(48.28)$ & 0.18 & 0.67 \\
Age (years) & & & \\
$\quad$ Males $(S D)$ & $49.2(1.76)$ & $48.8(1.99)$ & -0.58 & 0.57 \\
$\quad$ Females $(S D)$ & $47.8(1.74)$ & $48.5(1.97)$ & 0.85 & 0.40 \\
Handedness [N left (\%)] & $3(12.50)$ & $3(10.30)$ & 0.06 & 0.75 \\
Hollingshead Index of Social Position (ISP) & & & & \\
$\quad$ Education Index (SD) & $5.13(0.34)$ & $3.79(1.54)$ & -4.52 & $<0.0001$ \\
$\quad$ Occupational Index $(S D)$ & $6.25(1.03)$ & $4.31(1.58)$ & -5.36 & $<0.0001$ \\
$\quad$ Total Index $(S D)$ & $64.3(7.55)$ & $45.3(16.39)$ & -5.54 & $<0.0001$ \\
ISP Category $(S D)$ & $4.7(0.48)$ & $3.4(1.08)$ & -5.75 & $<0.0001$ \\
\hline
\end{tabular}

Note . Handedness statistical tests were done using Fisher Exact Test (non-parametric). There are 5 social position categories : (1) Upper, (2) Upper-middle, (3) Middle, (4) Lower-middle, and (5) Lower.

Table 2

Demographic Characteristics of NIRS Participants vs. Non-Participants from Original Cohort

\begin{tabular}{lcccc}
\hline Characteristic & Participant & Non-participant & t-test / $\chi 2$ & $p$ \\
\hline$N$ & 53 & 205 & & \\
Male (\%) & $27(50.90)$ & $126(61.50)$ & 1.93 & 0.165 \\
History of Malnutrition (\%) & $24(45.30)$ & $105(51.20)$ & 0.59 & 0.441 \\
Childhood Ecology (SD) & $-0.683(0.88)$ & $-0.528(1.00)$ & 1.11 & 0.268 \\
WISC Full-Scale IQ (SD) & $98.6(16.14)$ & $96.9(15.36)$ & -0.69 & 0.492 \\
\hline
\end{tabular}

Note. The Childhood Ecology and the Full-Scale IQ measures are from the 1977-1978 data collection, when participants were children.

Table 3

Mean and standard deviation of the behavioral measures for PEM and control group

\begin{tabular}{|c|c|c|c|c|c|c|}
\hline \multirow[b]{2}{*}{ Measure } & \multicolumn{2}{|c|}{$\operatorname{PEM}(N=24)$} & \multicolumn{2}{|c|}{ Control $(N=29)$} & \multirow[b]{2}{*}{$\begin{array}{c}\text { Mann- } \\
\text { Withney } U\end{array}$} & \multirow[b]{2}{*}{$p$} \\
\hline & $M$ & $S D$ & $M$ & $S D$ & & \\
\hline Reaction time (ms) & 357.95 & 35.24 & 357.83 & 38.30 & 352.00 & 0.94 \\
\hline Go accuracy (\%) & 97.09 & 3.22 & 98.25 & 2.59 & 462.00 & 0.04 \\
\hline No-Go accuracy (\%) & 76.64 & 12.11 & 80.21 & 12.87 & 420.00 & 0.20 \\
\hline
\end{tabular}


Table 4

Mean and standard deviation of the ERPs measures for Fz electrode

\begin{tabular}{lccccc}
\hline & \multicolumn{2}{c}{ PEM $(N=24)$} & & \multicolumn{2}{c}{ Control $(N=29)$} \\
\cline { 2 - 3 } \cline { 5 - 6 } Measure & $M$ & $S D$ & & $M$ & $S D$ \\
\hline No-Go Amplitude N2 & -1.84 & 1.44 & & -2.20 & 1.38 \\
Go Amplitude N2 & -1.48 & 0.92 & & -1.36 & 1.04 \\
No-Go Amplitude P3 & 2.72 & 2.21 & & 3.02 & 1.57 \\
Go Amplitude P3 & 0.83 & 1.06 & & 0.98 & 0.88 \\
No-Go Latency N2 & 313.88 & 36.03 & & 313.24 & 35.65 \\
Go Latency N2 & 291.75 & 36.40 & & 294.85 & 35.20 \\
No-Go Latency P3 & 417.24 & 26.30 & & 415.75 & 40.10 \\
Go Latency P3 & 416.34 & 36.34 & & 414.80 & 39.23
\end{tabular}

Table 5

Mean and standard deviation of the ERPs measures for FCz electrode

\begin{tabular}{lccccc}
\hline & \multicolumn{2}{c}{$\operatorname{PEM}(N=24)$} & & \multicolumn{2}{c}{ Control $(N=29)$} \\
\cline { 2 - 3 } \cline { 5 - 6 } Measure & $M$ & $S D$ & & $M$ & $S D$ \\
\hline No-Go Amplitude N2 & -2.04 & 1.78 & & -3.07 & 1.53 \\
Go Amplitude N2 & -1.53 & 0.97 & & -1.72 & 1.23 \\
No-Go Amplitude P3 & 3.38 & 1.52 & & 3.70 & 1.80 \\
Go Amplitude P3 & 1.33 & 0.97 & & 1.53 & 0.97 \\
No-Go Latency N2 & 305.09 & 37.43 & & 301.19 & 30.39 \\
Go Latency N2 & 279.70 & 41.46 & & 281.92 & 36.56 \\
No-Go Latency P3 & 417.48 & 24.47 & & 420.39 & 44.71 \\
Go Latency P3 & 416.10 & 37.53 & & 413.46 & 40.61
\end{tabular}

Table 6

Mean and standard deviation of the ERPs measures for $C z$ electrode

\begin{tabular}{lccccc}
\hline & \multicolumn{2}{c}{ PEM $(N=24)$} & & \multicolumn{2}{c}{ Control $(N=29)$} \\
\cline { 2 - 3 } \cline { 5 - 6 } Measure & $M$ & $S D$ & & $M$ & $S D$ \\
\hline No-Go Amplitude N2 & -2.19 & 1.63 & & -3.06 & 1.52 \\
Go Amplitude N2 & -1.61 & 1.02 & & -1.66 & 1.23 \\
No-Go Amplitude P3 & 3.74 & 2.19 & & 4.24 & 1.76 \\
Go Amplitude P3 & 1.21 & 0.91 & & 1.55 & 1.02 \\
No-Go Latency N2 & 307.94 & 36.42 & & 310.01 & 23.93 \\
Go Latency N2 & 287.60 & 37.51 & & 291.49 & 33.66 \\
No-Go Latency P3 & 426.76 & 34.67 & & 416.15 & 39.51 \\
Go Latency P3 & 415.93 & 37.06 & & 412.85 & 38.25
\end{tabular}




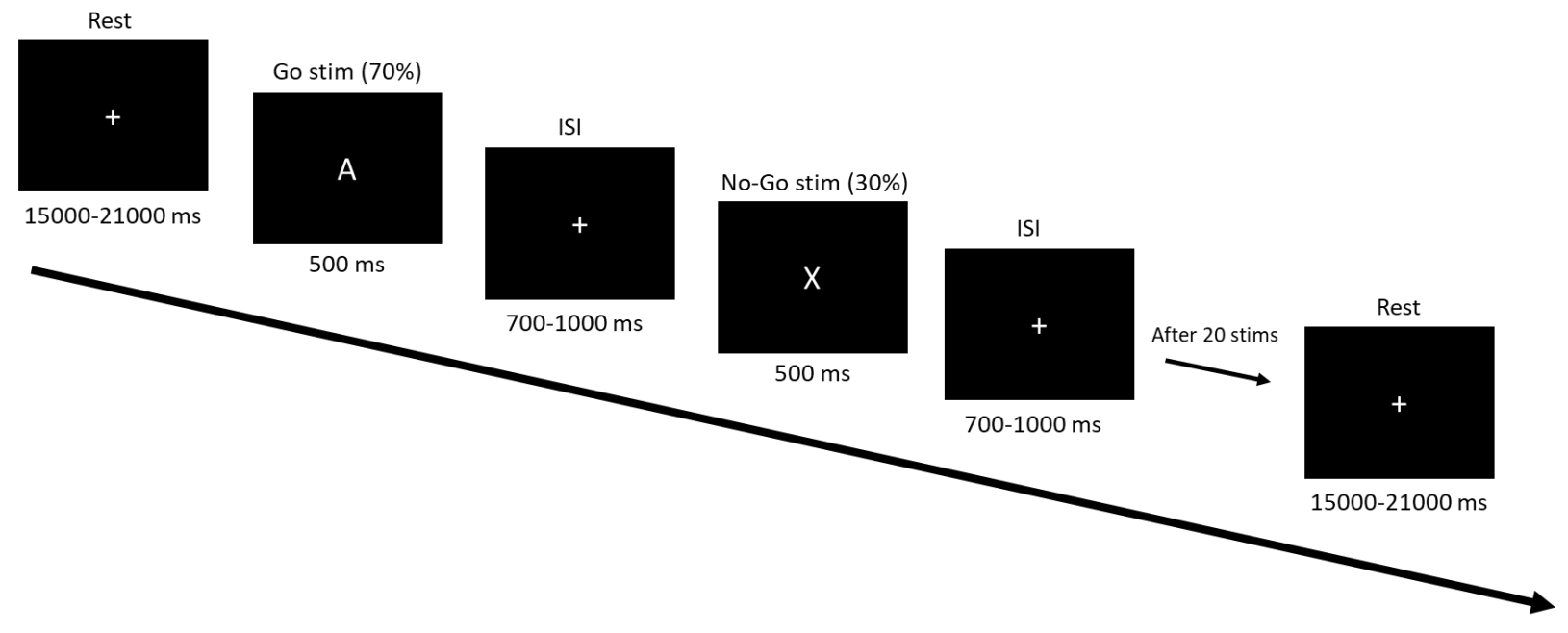

\section{Figure 1}

Go-No-Go task design 


\section{Controls}

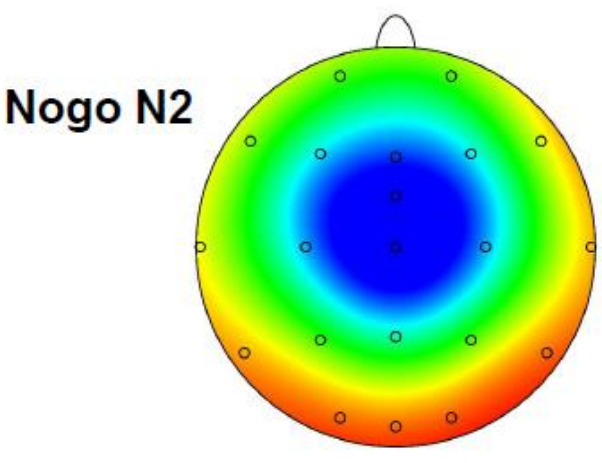

$305 \mathrm{~ms}$
PEM
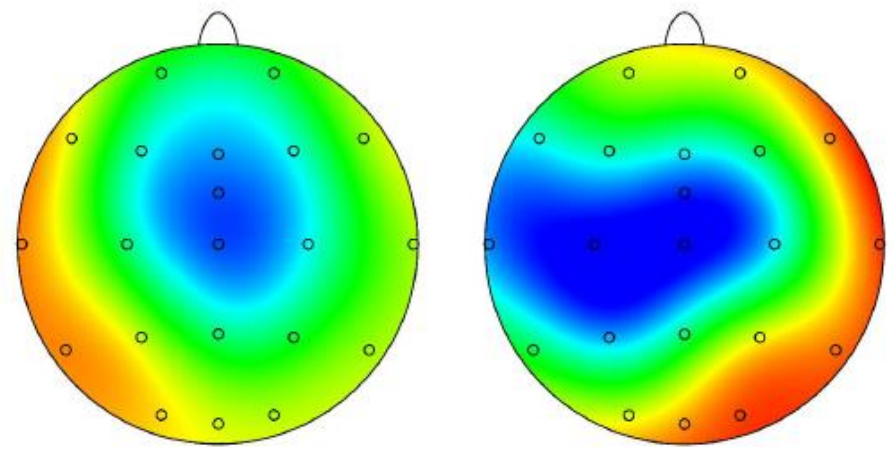

$311 \mathrm{~ms}$

T-test

$-2 \mu \mathrm{V}$
T-value

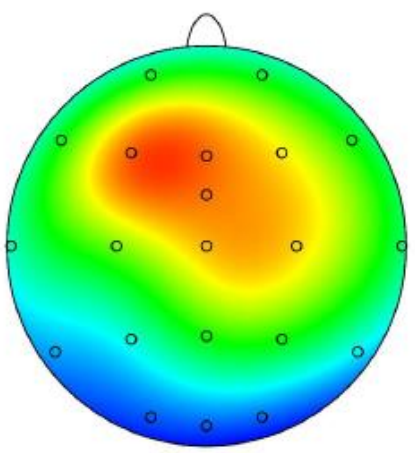

$377 \mathrm{~ms}$
$424 \mathrm{~ms}$

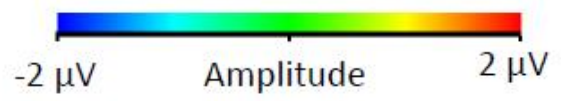

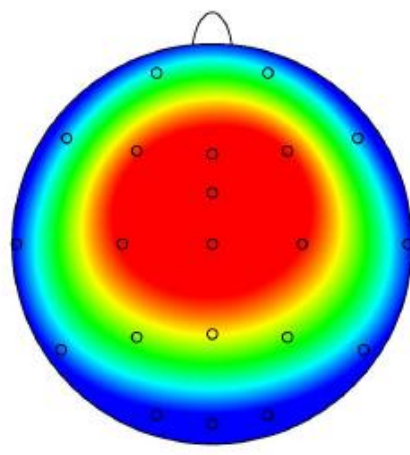

$-2 \mu \mathrm{V}$
T-value $2 \mu \mathrm{V}$

\section{Figure 2}

Topographic activation and topographic T-test (not corrected) of the difference of activation between PEM and control groups during No-Go condition 
Controls

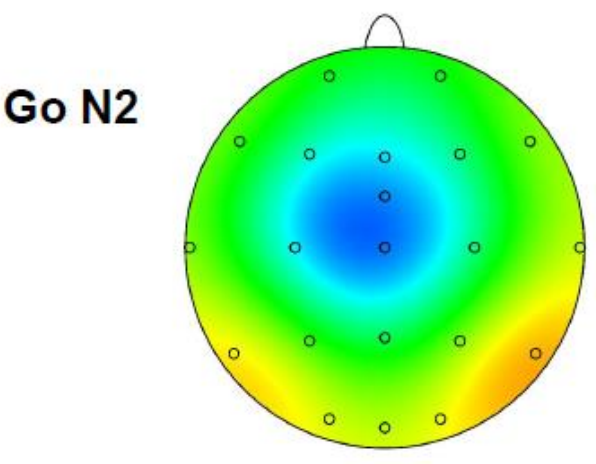

$273 \mathrm{~ms}$
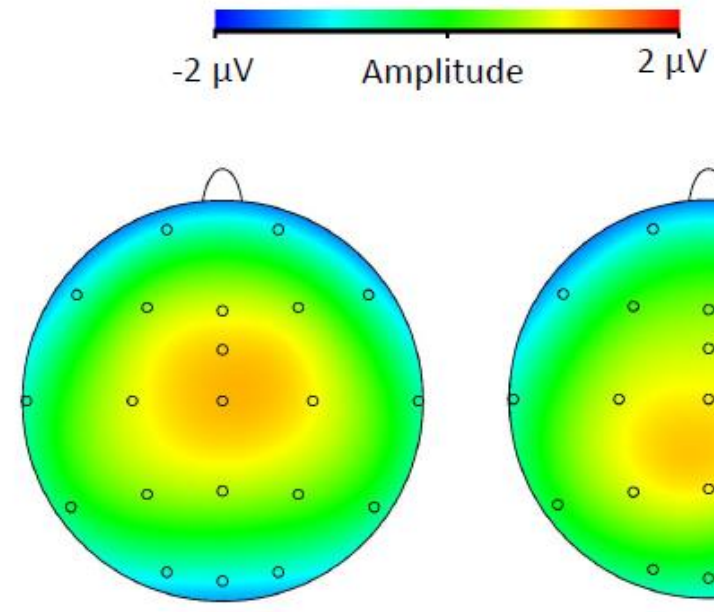

$414 \mathrm{~ms}$

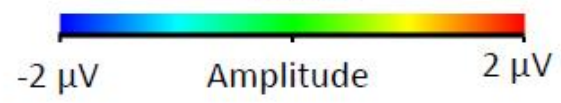

Go P3

Figure 3

Topographic activation and topographic T-test (not corrected) of the difference of activation between PEM and control groups during Go condition
PEM
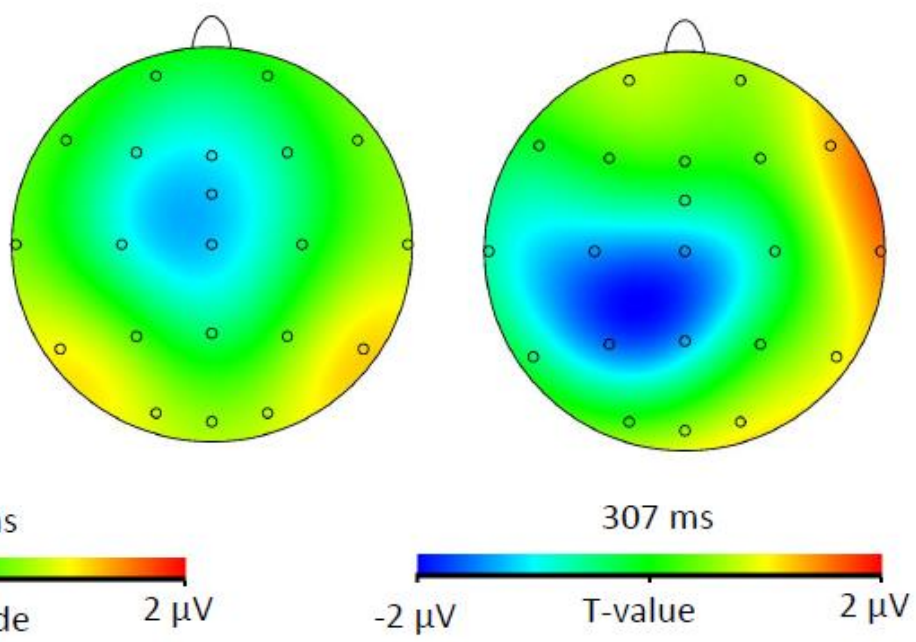

T-test

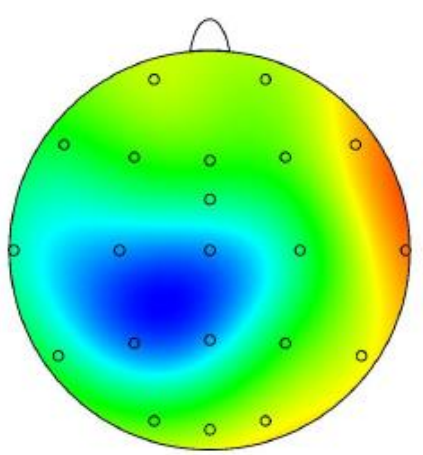

$307 \mathrm{~ms}$
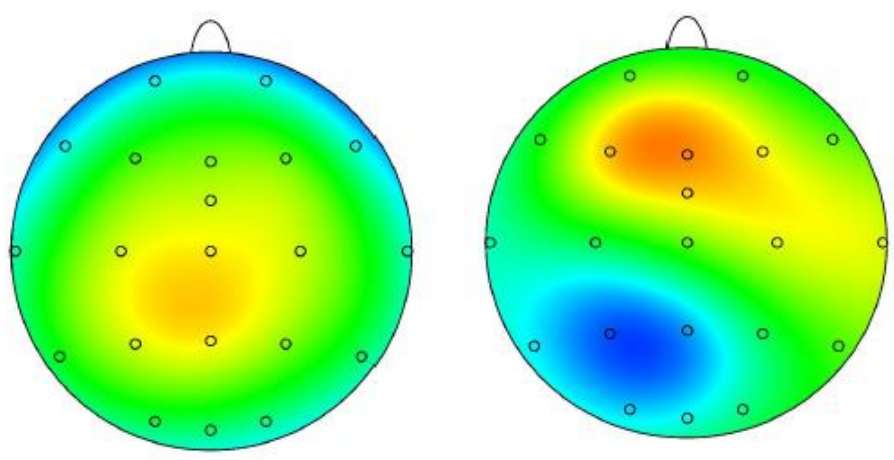

$380 \mathrm{~ms}$

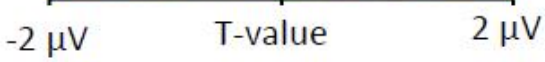




\section{Nogo Fz}

\section{Nogo FCz}

Nogo Cz

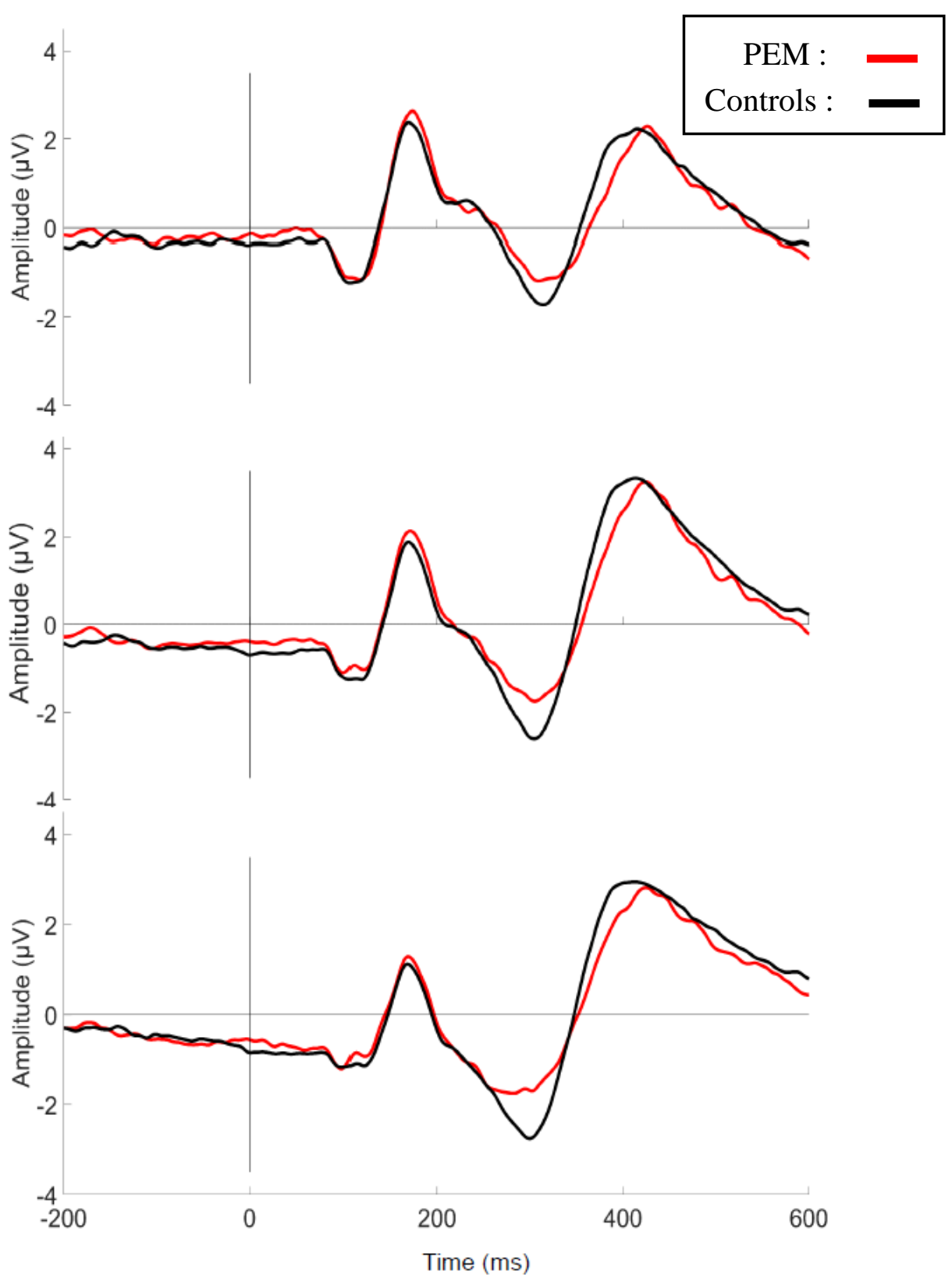

Figure 4

Grand average waveform of the N2 and P3 components during No-Go condition for each group 
Go Fz

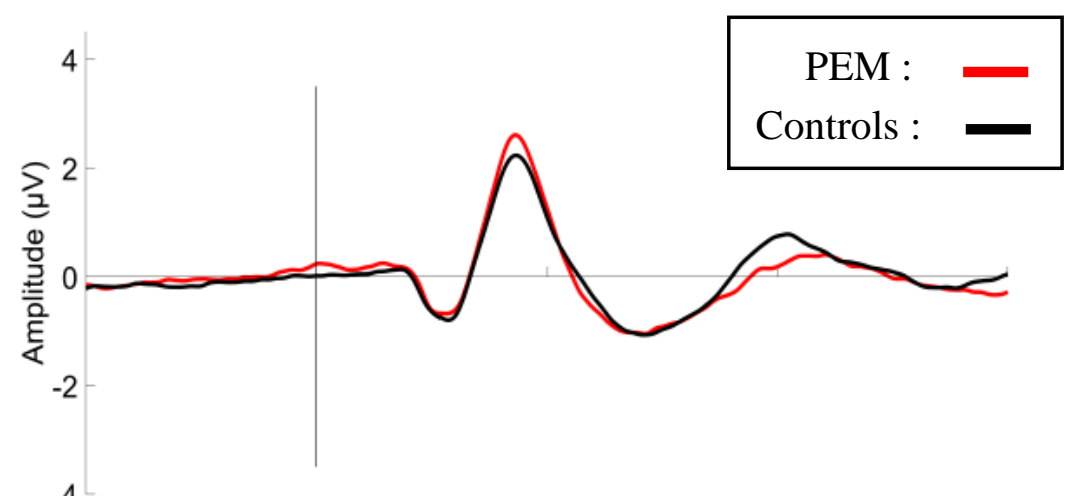

Go FCz

\section{Go $\mathrm{Cz}$}

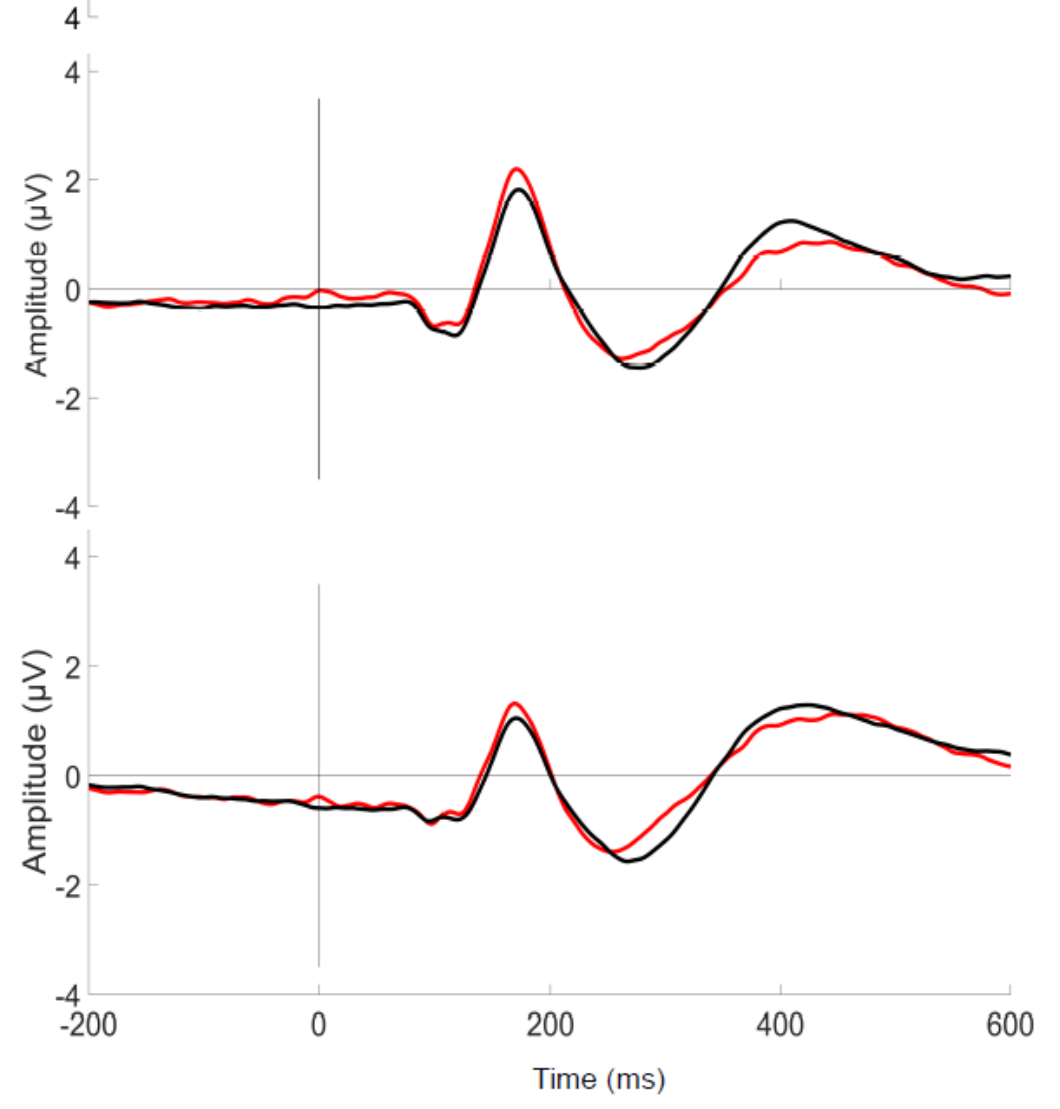

\section{Figure 5}

Grand average waveform of the N2 and P3 components during Go condition for each group 